\title{
Considerations on damage to bulb turbine shafts from iron Gates II
}

\author{
O D Negoita ${ }^{1}$, O R Chivu ${ }^{2}$, C Babiş ${ }^{2}$, A Dimitrescu ${ }^{3}$, L Dascalu $^{2}$, E Niculae $^{3}$, G \\ Iacobescu $^{2}$, A Semenescu ${ }^{4}$, and A Purcarea ${ }^{1}$ \\ ${ }^{1}$ Faculty of Entrepreneurship, Business Engineering and Management, Politehnica University \\ of Bucharest, Romania \\ ${ }^{2}$ Welding and Material Technology Department, Politehnica University of Bucharest, Romania \\ ${ }^{3}$ Theory of Mechanisms and Robots Department, Politehnica University of Bucharest, \\ Romania \\ ${ }^{4}$ Economics Engineering Department, Politehnica University of Bucharest, Romania \\ virlan_oana@yahoo.co.uk
}

\begin{abstract}
During operation, the turbine bulb shaft is subjected to static specific stresses (tension, compression, torsion) and dynamic (fatigue, random vibrations). These stresses are the effect of hydraulic forces and moments developed on the rotor blade, the weight of the rotor (with or without oil) in the console and inevitable vibrations, which creates a rotating mass unevenly distributed over the axis of symmetry of the turbine. Observations made on the turbine bulb shafts of the Iron Gate II CHE have revealed cracks in the connection area of a shaft flange that engages it with the turbine rotor. Examination of these cracks leads to the conclusion that they are specific to the inevitable fatigue demands in exploiting the tree and enhancing the environment in which they work. Therefore, in the paper, a presentation and analysis of the damage of bulb turbine shafts from CHE Porţile de Fier II, after a significant number of hours of operation.
\end{abstract}

Keywords: bulb turbine, fatigue, damage

\section{Introduction}

An element or assembly is deemed to have failed or is damaged if one of the three conditions is fulfilled:

- if it becomes completely inoperable;

- if it is still functional, but it can no longer work satisfactorily for a long time;

- if it has been seriously damaged and can no longer operate safely, requiring its immediate replacement and repair or mounting of a new item.

The basic sources of damage include many aspects of design, material selection, material imperfections, manufacturing and processing, assembling, inspection, testing, quality control, warehousing and shipping, conditions service, maintenance and unpredictable exposure to mechanical overload or chemical degradation in service. The basic sources of damage include many aspects of design, material selection, material imperfections, manufacturing and processing, assembling, inspection, testing, quality control, warehousing and shipping, conditions service, maintenance and unpredictable exposure to mechanical overload or chemical degradation in service.Often, more than one source contributes to the damage. Causes that can generally cause damage can be: design 
deficiencies, material deficiencies, material imperfections, machining deficiencies, errors that may occur during assembly, and improper service conditions.

An investigation of the cessation and its subsequent analysis should determine the primary cause of a cessation, and by acting decisively, the corrective action should be initiated so as to prevent similar disposals. Frequently, the auxiliary causes that cause failure also need to be evaluated. New experimental techniques can be developed or an unfamiliar domain of engineering or science can be explored. Investigating a complex accident, such as aviation, normally requires the service of experts in certain branches of engineering and the sciences of physics and metallurgy.

Although the succession of stages is variable depending on the nature of the specific cessation, the main stages of the investigation and analysis of a cession are as follows:

- collecting basic data and selecting samples;

- preliminary examination of the ceded piece (visual examination and compliance of the record);

- non-destructive testing;

- mechanical test (including hardness and tenacity);

- macroscopic examination and analysis (breaking surfaces, secondary cracks and other surface phenomena);

- examination and microscopic analysis;

- selecting and preparing metallographic samples;

- examining and analyzing metallographic samples;

- determination of the failure mechanism;

- chemical analysis (volume, local, surface corrosion products, deposits or coatings, and microprobe analysis);

- analysis of breakage mechanisms;

- Simulated service testing (special tests);

- analyzing all evidence, formulating conclusions and writing the report (including recommendations).

The time used to determine all the circumstances of failure is a well-spent time. When a broken component is received for examination, the investigator is sometimes inclined to prepare the specimens without initiating an investigative procedure. Such a lack of provision should be avoided, because in the end a great amount of time and effort can be wasted, while considering the foundation of the cessation and the study of the general features from the outset, a more informative procedure will be indicated.

When investigating component failures, visiting the site of failure may be impractical or impossible for the cessation analyst. In these cases, the data and samples can be collected by the field engineer or other on-site staff. A report scheme or a field checklist may be used to ensure that all relevant disclosure information has been recorded.

Initially, the investigation of the assignment should be directed to gaining knowledge with all relevant details of the disposal, by collecting information on the history of the manufacturing, treatment and service of the component or ceded structure, and the reconstruction as soon as possible of the sequence of events leading to the cession.

Collecting basic manufacturing data and manufacturing history of a component should begin with specifications and projects and should cover all design aspects of the component. The data on manufacturing and processing can be grouped into:

- mechanical processing that should include cold deformation, elongation, bending, chipping, polishing and grinding;

- thermal treatment which should include details of hot deformation, thermal treatments, welding, brazing or bonding;

- chemical treatments that should provide details on cleaning, electrochemical deposition, and application of coatings by alloying or chemical diffusion.

There are several causes that can cause damage to an installation. One of the most common causes is related to improper service conditions. Work of equipment under abnormally severe speed, stress, 
temperature and chemical environments, or without maintenance, inspection and monitoring on a regular basis, makes a major contribution to the production of failures in service. Inspection and monitoring procedures can be of little or no value if they are not based on a global consideration of the various damage mechanisms that may be possible for the considered piece. Such procedures should be capable of detecting significant damage during inspection and maintenance operations at regular intervals.

Among the unfit terms of service, we mention:

- Putting into operation different equipment

Putting into operation of various equipment, especially complex ones, consists of starting the equipment for the first time in service, starting after the equipment has been shut down for maintenance or starting the equipment when it comes to operating procedures intermittently, this being a critical issue. During start-up, equipment may be subject to conditions not encountered in normal work, including rapid changes in working parameters, extreme temperature gradients and other abnormal conditions. Without well-controlled implementation of the correct startup procedures, it is very likely to determine the malfunctioning and possible failure of such components.

We can exemplify the damage resulting from the deformation and breakage of carbon steel pipes in a marine reheating boiler due to extreme local and rapid overheating during start-up. The failure of these pipes has caused a large degradation of the boiler.

Stopping and maintenance procedures

The procedures for stopping and maintaining the specific conditions for the downtime (especially for complex equipment) essentially had the same delivery potential as the commissioning procedures. We can exemplify the damage caused by corrosion by the cumulative severe pitting of medium carbon steel pipes in an exhaust pipe boiler that developed during a few annual stops for capital repair.

- Inappropriate maintenance

Improper maintenance is often the factor contributing to service failures. Maintenance procedures should be fully re-evaluated when damage has resumed, despite regular maintenance.

We can exemplify through the damage at the grooved ends of 5 engine shafts of a starter generator that yielded before a full analysis determined the cause of the failure and this led to the specification of the mandatory relubrection at each 300 hour inspection instead of only one at the initial installation.

\section{Experimental research}

During operation, the bulb turbine shaft is subjected to static specific stresses (stretching, compression, torsion) and dynamic (fatigue, random vibrations). These stresses are the effect of the hydraulic forces and moments developed on the rotor blades, the weight of the rotor (with or without oil) in the console, Figure 1, and the inevitable vibrations created by the rotating masses and unevenly distributed over the axis of symmetry of the turbine.

The observations made on the bulb turbine shafts of the Iron Gate II CHE have revealed cracks in the connection area of the shaft flange that engages it with the turbine rotor. Examining these cracks has led to the conclusion that they are specific to the inevitable fatigue demands in exploiting the tree and amplified by the wet environment in which they work. Therefore, the paper presents and analyzes the damages suffered by the bulbous turbine shafts at CHE Porţile de Fier II, after a significant number of hours of operation.

Table 1 shows the operating parameters of the bulb turbine and the main technical data.

The bulb turbine shaft, Figure 1, is made of two components: a casting consisting of the turbine rotor coupling flange and a cylindrical and a forged portion formed by the coupling flange with the electric generator shaft and most of the cylindrical part with which it engages and in the axial radial bearing.

The mechanical characteristics and chemical composition of the shaft steel are: mechanical breaking strength $\mathrm{Rm}=470,88 \mathrm{~N} / \mathrm{mm} 2$, flow limit Rp0,2 $=255,05 \mathrm{~N} / \mathrm{mm} 2 ; \mathrm{C}=0.16 \ldots 0.22 \%, \mathrm{Mn}$ $=1 \ldots 1.3 \%, \mathrm{Si}=0.60 \ldots 0.80 \%, \mathrm{Cr}, \mathrm{Ni}, \mathrm{Cu}<0.3 \%, \mathrm{~S}, \mathrm{P}<, 03 \%$. 
The analysis of the chemical constitution shows that the material used is a manganese weakly alloyed steel.

The proportion of chromium and nickel (especially chromium) is insufficient to confer increased corrosion resistance including intercrystalline corrosion. Given the influence of manganese on crystalline grains, we appreciate that the main alloying element determines a rough structure of the flange blank. In the case of castings, this structure determines both large crystalline grains and some unevenness in their dimensions. Preserving the initial composition, with small percentages of chromium and nickel, makes the corrosion resistance, Figure 2, remain relatively low, which does not improve the propagation of the cracks initiated.

Table 1 Operating parameters of a bulb turbine

\begin{tabular}{ccc}
\hline Parameter & Symbol & Value \\
\hline The net fall & $\mathrm{H}$ & $7,8 \mathrm{~m}$ \\
\hline Flow & $\mathrm{Q}$ & $475 \mathrm{~m} 3 / \mathrm{s}$ \\
\hline Useful power & $\mathrm{P}$ & $32,5 \mathrm{MW}$ \\
\hline Turbine speed & $\mathrm{nT}$ & $62,5 \mathrm{rpm}$ \\
\hline Rotor pallet weight & Gpal & $7545 \mathrm{~kg}$ \\
\hline $\begin{array}{c}\text { Weight rotor sub-assembly } \\
\text { (oil-free) }\end{array}$ & Grotor & $99,6 \mathrm{t}$ \\
\hline Tree diameter & $\mathrm{d}$ & $1200 \mathrm{~mm}$ \\
\hline Flange diameter & $\mathrm{D}$ & $1700 / 2298 \mathrm{~mm}$ \\
\hline
\end{tabular}

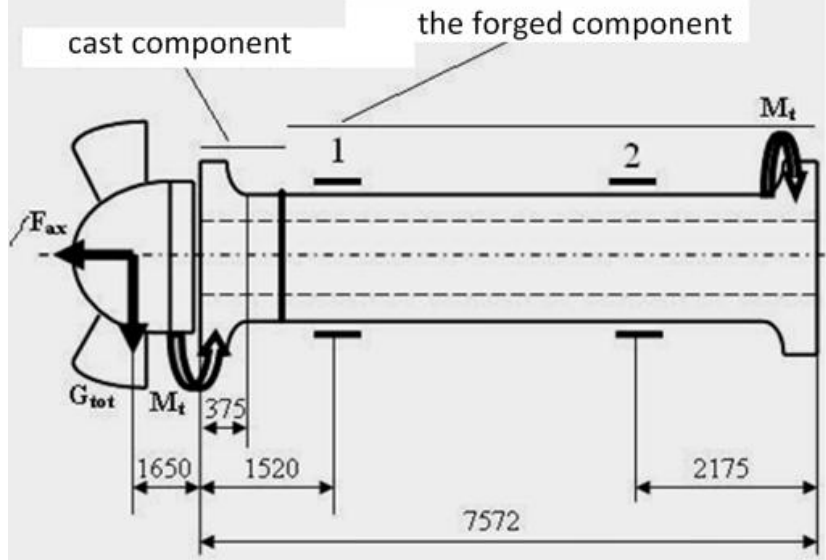

Figure 1. Bulb turbine shaft construction

\section{Experimental results}

As a result of the journeys carried out, the examined examinations and the discussions held at the Portile de Fier II CHE premises, the cracks appeared after a continuous operation of the aggregates, different from one aggregate to another.

Also, turbine operation has been consistent with specific, continuous, controlled and controlled regimes. As a result, the incriminated areas were checked by non-destructive specific methods, at each stop of the Romanian aggregates. After a control of about 130,000 to 140,000 hours of operation, a network of circumferential cracks was observed in the coupling flange of the shaft with the turbine rotor. This has led us to appreciate that crack initiation was caused by specific requirements, material constitution, processing technology and working conditions (humidity), as seen in Figure 2.

The appearance of the cracked areas has fatigue traits, similar to those described in Fractogaphs and Metals Handbook, vol. 9, Metals Park Ohio, ATME, 1986, where several elements can be seen in the following:

- lack of macroscopic plastic deformations or dimensional changes (cracks, etc.), as seen in Figure 3; 


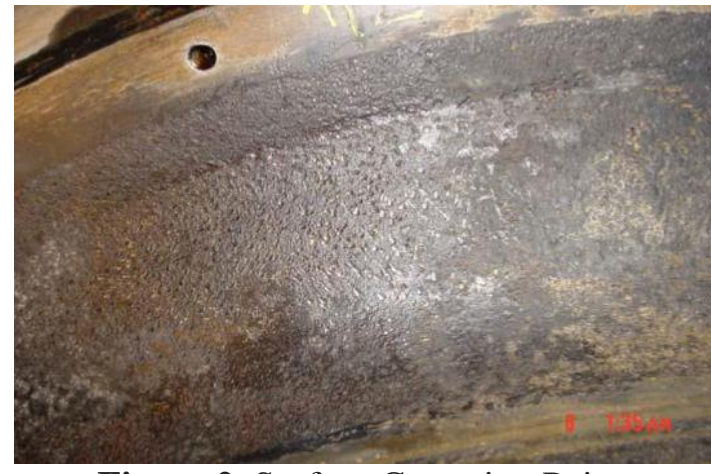

Figure 2. Surface Corrosion Points

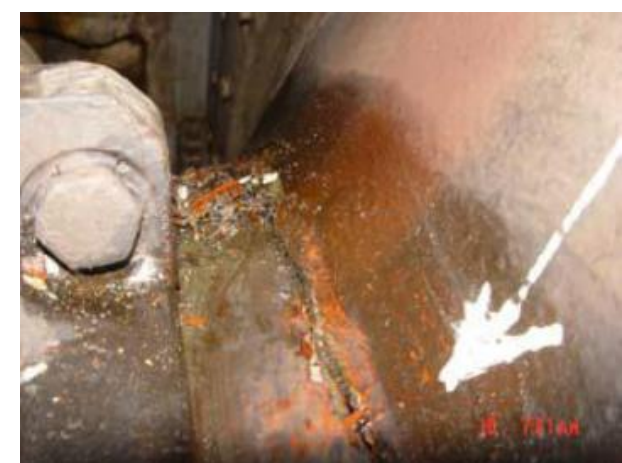

Figure 3. Cracks in the connection area of the shaft flange

- macroscopically, the breakage surface of the piece has two areas, one with a relatively smooth (even polished) appearance of slow crack propagation, and the second with the appearance of fracture breaks (grungy surface), as seen in Figure 4;

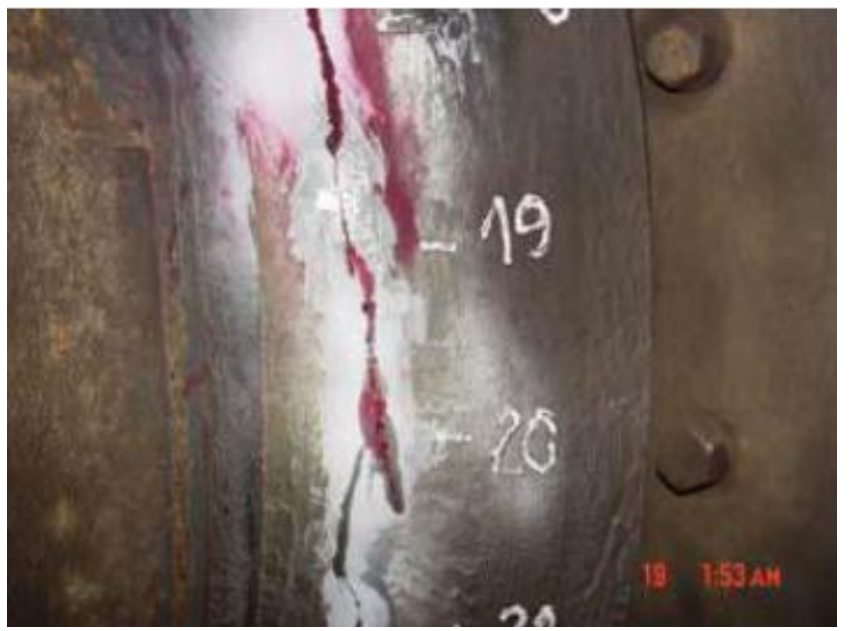

Figure 4. Macroscopic appearance of the breaking surface

- the smooth zone exhibits some bumps that progressively increase with the removal from the crack initiation site (the best-polished area is in the immediate vicinity of the initiation point), as seen in Figure 4;

The examination of the cracks in Figures 3 and 4, based on the photographs taken on the hydroaggregate tree no. 6 , allowed to substantiate the causes that led to cracks in the flange connection area of such a magnitude.

Analyzing the image in Figure 3a we can see:

- The zigzag shape of the circumferential crack is more evident, reflecting the existence of microzones with increased strength that required circumvention;

- Chemical corrosion occurred even under the protective coating layer;

- There are cracks in areas close to the second radius of connection (near the arrow). This aspect shows the high degree of stress generated by the high stresses induced by the high stresses on which the tree part is in the console.

Analyzing the image in Figure 4 we can see the following:

- Cracks were generated and developed in different plans;

- The propagation path took place differently, perhaps due to the encounter of hard grains / harsh intergranular connections caused by the presence of manganese as the main chemical alloying element and that caused it to change; 
- The shape of cracks is clearly a specific fatigue requirement;

- The darker color of the solution used to identify and assess damage indicates that the crack depth is significant, which in practice has forced the shaft out of service and repair the defect;

\section{Conclusions}

We appreciate that the cracking produced in the spindle-shaft flange connection area is caused by specific stresses, the chemical and structural constituent of the material, the processing technology and the working conditions (humidity).

The flange connection area, where the cracks appear, works in wet environments, which also involves corrosive activity, which contributes to increased cracking during the operation of the aggregate.

Small crack removal operations are required because they can develop on a spring the circle of the circumference of the shaft taking an irregular shape, caused by propagation through areas of lesser or greater resistance, ultimately leading to the breaking of the shaft.

The initiation and development of circumferential cracks can be accomplished in one or more planes. This form of development and development is specific to the parts made of semi-finished products with structural and technological defects of machining (chromium carbides, large and nonhomogeneous crystalline grains, improper machining, etc.) and subjected to unsymmetrical cyclical stresses caused by the mounting conditions and the distribution of the masses in motion composed by rotation - bending-stretching (axial pushing).

The multitude of cracks is determined by the initial primers, created primarily by the mechanical machining technology (roughness level), but also by the tenacity of the material.

\section{References}

[1] Monika O., Peter P.,Milan U.,Fracture mechanism differences created by fatigue and impact test, Materialstoday Proceedings, vol. 4/issue 3, pp 5921-5924, 2017

[2] Zhao-Ling W, Heng X,Direct modeling of multi-axial fatigue failure for metals, International Journal of Solids and Structures, pp 216-231, 2017

[3] Pavel, A., Siguranţa în funcţionare a utilajelor petrochimice, Editura Tehnică, vol 3, pp 5-365, 1988

[4] Armando L., Rama I., José A., Carlos A., Branco G., Fatigue behaviour of $T$ welded joints rehabilitated by tungsten inert gas and plasma dressig, Materials and Design, vol 32, pp 4705-4713, 2011

[5] Barsom, J.M., Rolfe, S.T., Fracture and Fatigue Control, Edition 2, Prentice Hall, 1987.

[6] Bathias, C., Paris, P.C., Gigacyclic Fatigue in Mechanical Practice, Marcel Decker, New York, 2005.

[7] Rusu, O., Teodorescu, M., Laşcu-Simion, N., Oboseala metalelor, vol.1, Editura tehnică, Bucureşti, 1992.

[8] Mitelea, I., Budau, V., Studiul metalelor, Îndreptar tehnic, Editura Facla, Timișoara, 1987.

[9] ***, Fatigue Design Handbook, Second Edition, SAE, Warrendale, 1988.

[10] Bejan, M., În lumea unităţilor de măsură. Ediţia a doua revăzută şi adăugită. Editura Academiei Române şi Editura AGIR, Bucureşti, 2005.

[11] Armando L., Rama I., José A., Carlos A., Branco G., Fatigue behaviour of $T$ welded joints rehabilitated by tungsten inert gas and plasma dressig, Materials and Design, vol 32, pp 4705-4713, 201 